\title{
PENERAPAN M-HEALTH UNTUK DIAGNOSTICS AND TREATMENT SUPPORT PADA NEGARA BERKEMBANG: STUDI KASUS INDONESIA
}

\author{
Alfadesta $^{1}$, Aprilianto ${ }^{1}$, Danny Handoko ${ }^{1}$, F.S. Rifano ${ }^{1}$, dan Sani M. Isa ${ }^{2}$ \\ ${ }^{1}$ Program Studi Sistem Informasi, Universitas Indonesia, Kampus Baru UI Depok, Jawa Barat, 16424, \\ Indonesia \\ ${ }^{2}$ Program Studi Teknik Informatika, Fakultas Teknologi Informasi, Universitas Tarumanagara, \\ Jl.Letjen.S.Parman No. 1 Blok R Lantai XI Grogol, Jakarta Barat, 11440, Indonesia
}

E-mail: alfadesta@ui.ac.id

\begin{abstract}
Abstrak
Diagnosis dan dukungan perawatan merupakan salah satu faktor utama dalam hal perawatan kesehatan. Metode tradisional diagnosis secara tatap muka antara pasien dan dokter dalam rangka monitoring dan menjaga kestabilan kesehatan sudah mulai sulit untuk dilakukan. Hal ini dikarenakan banyaknya hambatan-hambatan yang muncul, baik hambatan finansial, geografi, dan waktu. Teknologi informasi khususnya telekomunikasi dapat membantu mengatasi permasalahan tersebut, yang secara tidak langsung akan dapat membantu pengembangan sistem kesehatan di sebuah negara. Salah satu solusi yang dapat digunakan adalah penerapan $m$-Health pada sistem kesehatan. $m$-Health didefinisikan sebagai sebuah penggunaan mobile communications and network technologies dalam melakukan perawatan kesehatan. Pola penerapannya menggunakan mobile phone sebagai point-ofcare device. Hanya saja, penerapan sebuah teknologi baru dalam suatu negara tidak dapat begitu saja dilakukan. Terdapat faktor-faktor yang perlu diperhatikan agar penerapan teknologi baru dapat berjalan secara optimal. Penelitian bertujuan untuk mengetahui sejauh mana kelayakan penerapan $m$ Health untuk diagnosis dan dukungan perawatan kesehatan pada negara berkembang dengan menggunakan studi kasus negara Indonesia. Penelitian ini dilakukan dengan menggunakan metodologi causal comparative terhadap penerapan $m$-Health di negara maju. Analisis kelayakan akan dilakukan terhadap empat aspek, yakni aspek ekonomi, teknologi, sosial, serta organisasi.
\end{abstract}

Kata Kunci: diagnostics and treatment support, kesehatan, $m$-health

\begin{abstract}
Diagnosis and treatment support is one of the main factors in health care. Traditional methods of diagnosis in person between patients and physicians in order to monitor and maintain health stability is getting hard to do. This is because many of the obstacles that arise, whether financial constraints, geography, and time. Telecommunications in particular information technology can help overcome these problems, which will indirectly help the development of health systems in the country. One solution that can be used is the application of m-Health in the health system. m-Health is defined as the use of mobile communications and network technologies in the conduct of health care. Pattern application is using mobile phones as point-of-care device. Only, the application of a new technology in a country can not simply be done. There are factors that need to be taken to ensure that the application of new technologies can run optimally. The study aims to determine the extent to which the feasibility of applying the $\mathrm{m}$-Health for the diagnosis and support for health care in developing countries by using a case study of Indonesia. The research was conducted using causal comparative methodology for the application of m-Health in developed countries. Feasibility analysis will be conducted on four aspects, namely the economic, technological, social, and organizational.
\end{abstract}

Keywords: diagnostics and treatment support, health, $m$-health

\section{Pendahuluan}

Kesehatan merupakan sebuah kondisi fisik, mental, serta kesejahteraan sosial seseorang yang terbebas dari penyakit. Kesehatan merupakan hal yang utama bagi setiap individu dalam menjalankan aktivitas sehari-hari. Ketika seseorang jatuh sakit, maka akan dibutuhkan banyak biaya serta waktu untuk proses pemulihan kesehatan. Dengan meningkatnya kemungkinan seseorang terkena penyakit, setiap individu harus selalu menjaga dan mengetahui kondisi kesehatannya sendiri. Selain dengan mengembangkan pola hidup sehat, masyarakat juga harus melakukan pemeriksaan kesehatan secara teratur. Melalui pemeriksaan secara rutin, 
setiap orang akan mengetahui gambaran mengenai kondisi kesehatannya [1].

Namun, pada umumnya masyarakat jarang melakukan pemeriksaan rutin karena beberapa hambatan, seperti jarak rumah sakit atau pelayanan kesehatan yang cukup jauh, biaya yang tidak sedikit, serta waktu yang terbatas. Padahal, pemeriksaan secara rutin dapat mencegah dan mengantisipasi perkembangan suatu penyakit. Sehingga, ketika suatu penyakit menyerang, tindakan preventif dapat dilakukan sesegera mungkin.

Dukungan teknologi informasi khususnya telekomunikasi dapat menjadi salah satu solusi untuk menyelesaikan hambatan-hambatan yang telah disebutkan sebelumnya. Penerapan teknologi diharapkan dapat membantu kita untuk menjaga dan merawat kesehatan. Salah satu teknologi yang dapat diterapkan adalah teknologi m-Health. mHealth didefinisikan sebagai sebuah penggunaan mobile communications and network technologies dalam melakukan perawatan kesehatan. Teknologi $m$-Health memungkinkan seseorang untuk melakukan monitoring terkait kesehatannya tanpa harus pergi ke rumah sakit atau bertemu dengan dokter. Dengan menggunakan sistem $\mathrm{m}$-Health, pasien hanya perlu menggunakan sebuah mobile device yang akan mengakses ke sebuah medical database. Setelah diolah, jawaban mengenai kondisi kesehatan pasien akan dikirimkan. Dengan demikian, pasien dapat terus memantau kondisi fisiknya tanpa harus bertemu secara langsung dengan dokter.

Implementasi sistem $m$-Health pada negara berkembang dapat membantu proses medis di negara tersebut khususnya apabila sumber daya rumah sakit serta sumber daya dokter sangat terbatas. Di Indonesia, pada beberapa provinsi yang belum stabil, seperti Gorontalo dan Nusa Tenggara Barat, tingkat kematian bayi dan anakanak tercatat 4-5 kali lebih tinggi dibandingkan dengan provinsi yang sudah baik, seperti Bali dan Yogyakarta [2]. Hal ini dipengaruhi oleh beberapa faktor, antara lain, terbatasnya sumber daya manusia yang kompeten di bidang kesehatan serta sedikitnya akses informasi kesehatan yang tersedia.

Walaupun terlihat sangat menjanjikan, penerapan teknologi $\mathrm{m}$-Health tidak serta merta dapat diterapkan. Terdapat beberapa faktor yang harus diperhatikan agar proses penerapan $m$ Health berjalan dengan optimal. Hal ini perlu diperhatikan karena penerapan $m$-Health bukan sesuatu yang murah dan mudah untuk dilakukan. Sehingga penerapannya harus berjalan secara efektif.

Berdasarkan latar belakang tersebut, penulis melakukan sebuah penelitian untuk menganalisis kelayakan penerapan $m$-Health untuk diagnosis dan dukungan perawatan di negara-negara berkembang, dengan studi kasus negara Indonesia. Pemilihan Indonesia didasarkan pada kondisi geografis Indonesia yang terdiri dari gugus kepulauan, yang merupakan salah satu hambatan dalam melakukan pelayanan kesehatan kepada masyarakat.

Dalam melakukan penelitian ini, penulis memilih India, Australia, dan Amerika sebagai negara pembanding, hal ini karena negara-negara tersebut sudah mendukung penggunaan $m$-Health.

Tujuan yang ingin dicapai pada penelitian ini yaitu untuk mengetahui kelayakan penerapan $m$ Health untuk Diagnostics and Treatment Support pada negara berkembang dengan studi kasus di Indonesia. Penelitian ini juga ditujukan untuk mengetahui bagaimana penerapan $m$-Health yang dapat dilakukan di Indonesia. Dengan dilakukannya penelitian ini diharapkan hasil dari analisis yang telah dipaparkan dapat digunakan sebagai dukungan referensi dalam menerapkan $m$ Health di Indonesia. Pada penelitian ini dibatasi pada ruang lingkup sebagai berikut: penelitian yang dilakukan terbatas pada analisis kelayakan penerapan m-Health di Indonesia, tidak sampai tahapan implementasi penerapan; penelitian aspek kelayakan penerapan m-Health di Indonesia terbatas pada diagnostics dan treatment support; serta aspek kelayakan yang akan diteliti pada penerapan $m$-Health di Indonesia ini terbatas pada aspek ekonomi, teknologi, sosial, dan organisasi.

Weighted scoring method merupakan metode untuk melihat nilai dari suatu hal, berdasarkan indikator-indikator atau kriteria-kriteria yang mempengaruhinya. Metode ini menggunakan dua variabel dalam proses analisis, yakni bobot dan nilai indikator.

\section{Case: Kelayakan Penerapan m-Health}

TABEL I

PEMETAAN INFRASTRUKTUR IT

\begin{tabular}{llll}
\hline Indikator & $\begin{array}{l}\text { Nilai } \\
\text { Indikator } \\
\left(\mathrm{a}_{\mathrm{k}}\right)\end{array}$ & $\begin{array}{l}\text { Bobot } \\
\left(\mathrm{b}_{\mathrm{k}}\right)\end{array}$ & $\begin{array}{l}\text { Weighted } \\
\text { Score }\end{array}$ \\
\hline $\begin{array}{l}\text { Tingkat } \\
\begin{array}{l}\text { Pendapatan } \\
\text { Perkapita }\end{array}\end{array}$ & 8 & 30 & 240 \\
\hline Infrastruktur & 5 & 30 & 150 \\
\hline $\begin{array}{l}\text { Technology } \\
\text { Acceptance }\end{array}$ & 6 & 40 & 240 \\
\hline Total Weighted Score & & 630 \\
\hline
\end{tabular}

Bobot mendeskripsikan suatu nilai yang didasarkan pada tingkat kepentingan/kontribusi dari masing-masing indikator terhadap suatu hal. Sedangkan nilai indikator, menggambarkan besar kecilnya nilai dari setiap indikator. 
Tabel I menunjukkan contoh penerapan weighted score pada kasus kelayakan penerapan m-health. Kasus ini dipengaruhi oleh tiga indikator, yakni tingkat pendapatan per kapita, infrastruktur dari daerah pelaksana, serta tingkat penerimaan akan teknologi baru oleh masyarakat. Setiap indikator diberikan sebuah bobot berdasarkan tingkat kepentingannya. Total bobot yang ditetapkan untuk seluruh indikator harus mencapai nilai 100. Kemudian, nilai untuk setiap indikator di-assign berdasarkan performance atau kondisi yang sebenarnya.

$$
\text { Total Weighted Score }=\sum_{k=1}^{n} \mathrm{a}_{\mathrm{k}} \mathrm{b}_{\mathrm{k}}
$$

Dalam proses analisis, nilai indikator akan dikalikan dengan bobot untuk mendapatkan weighted score dari setiap indikator. Total weighted score didapatkan dengan menjumlahkan semua weighted score. Total weighted score akan dibandingkan dengan suatu standard untuk mengetahui apakah case tersebut lebih baik atau dalam penelitian ini dikatakan layak untuk diimplementasikan.

Diagnostic merupakan langkah awal dalam penanganan kesehatan. Kesalahan melakukan diagnosis bisa "menyebabkan konsekuensi yang fatal, bahkan serius". Sedangkan, treatment support adalah proses yang harus dilakukan setelah diagnosis dilakukan.

Dalam area ini, aplikasi m-Health memberikan akses ke sebuah "medical information database yang bertujuan untuk memberikan diagnostic and treatment advice" [3]. Aplikasi ini memanfaatkan mobile phone sebagai sebuah alat penghubung antara pasien dan dokter. Mobile phone milik pasien akan dilengkapi oleh sebuah software, yang dapat mengirimkan data untuk diolah. Hasil pengolahan data berupa diagnosis dan saran penanganan atau pengobatan, akan dikirimkan ke mobile phone pasien yang mengalami gejala-gejala tertentu. Pada akhirnya, pasien bisa mengetahui dan turut berperan aktif terhadap peningkatan mutu kesehatannya.

Melalui aplikasi ini, biaya-biaya yang harus dikeluarkan untuk melakukan pemeriksaan kesehatan dapat dikurangi. Di samping itu, permasalahan mengenai pertemuan dokter dan pasien dapat diminimalisir sehingga "akses kesehatan bagi masyarakat bisa meningkat".

Implementasi m-Health di Indonesia memberikan harapan terhadap perbaikan kondisi kesehatan masyarakat. Walaupun demikian, penerapan $m$-Health sebagai teknologi baru perlu dikaji lebih dalam agar dapat berjalan secara optimal.

Dalam pengkajiannya, terdapat empat aspek yang harus diperhatikan dalam penerapan teknologi mobile health di suatu negara [4]. Pertama, aspek sosial. Teknologi mobile merupakan bagian yang tidak terpisahkan dalam kehidupan masyarakat. Mobilitas yang tinggi, tanpa memandang kalangan, menjadi hal yang sudah biasa. Pengaruh dari teknologi mobile health berdampak pada beberapa hal seperti, tidak terbatasnya lokasi health care [4][5], penggunaan informasi penanganan kesehatan yang cepat, dan sebagainya.

Kedua, aspek teknis. Kelayakan suatu perangkat berbasis mobile untuk diterapkan disuatu negara ditentukan oleh aspek yang paling mendasar, yakni kemampuan infrastruktur suatu negara. Kolaborasi antara fungsionalitas teknologi dan kenyamanan penggunanya menjadi hal yang harus diperhatikan, agar tidak menjadi suatu teknologi yang malah mengganggu kenyamanan dan kehidupan masyarakat [6][7].

Aspek ketiga adalah aspek ekonomi. Sebuah teknologi baru membutuhkan dukungan finansial dalam proses penerapannya. Kemampuan finansial masyarakat menjadi faktor yang penting untuk diperhatikan selain kondisi ekonomi dalam suatu negara. Aspek terakhir adalah aspek organisasi. Aspek organisasi menjadi penting karena penerapan teknologi mobile harus diiringi dengan perubahan bisnis proses dari organisasi dunia kesehatan, terutama klinik kesehatan dan rumah sakit. Selain itu, dukungan terhadap organisasi kesehatan selama proses penerapan $\mathrm{m}$ Health menjadi faktor kunci [4].

\section{Metodologi}

Untuk mendapatkan indikator-indikator yang sesuai, peneliti memilih menggunakan acuan Health Technology Assesment (HTA). HTA mencocokkan antara sisi ekonomi dengan konsekuensi dari sisi penanganan medis dan teknologi [8][9]. Proses dalam HTA mengedepankan peran pasien yang dalam hal ini juga sebagai pengguna mobile health itu sendiri. Indikator dari setiap aspek dijelaskan pada tabel II. Indikator yang sudah didapatkan tadi selanjutnya akan diberi bobot, sesuai proporsi kontribusinya dalam mempengaruhi penerapan mobile health di sebuah negara. Pemberian bobot didasarkan pada beberapa pertimbangan pada referensi yang peneliti dapatkan. Tabel III menunjukkan bobot masing-masing indikator pada tabel II. 
TABEL II

INDIKATOR FAKTOR KELAYAKAN Indikator faktor kelayakan

Ekonomi

- Pendapatan Per Kapita Masyarakat

- Proporsi Pendapatan untuk Kebutuhan Tersier

- Angka Rata-rata Pertumbuhan Ekonomi per Tahun

- Jumlah Biaya Rata-rata untuk Kesehatan per Bulan

Teknologi

- Jumlah Pengguna Mobile Phone

- Harga Rata-rata Paket Internet Mobile Phone per Bulan

- Jumah Wireless Router

Sosial

- Jumlah Masyarakat Miskin

- Jumlah Perbandingan Hospital Bed per 10,000 populasi

- Jarak Rata-rata Rumah Penduduk dengan Rumah Sakit

Organisasi

- Anggaran Pemerintah untuk Kesehatan

- Anggaran Pemerintah untuk Teknologi

TABEL III

BOBOT SETIAP INDIKATOR

\begin{tabular}{|c|c|}
\hline Indikator faktor kelayakan & Weight \\
\hline $\begin{array}{l}\text { Ekonomi } \\
\text { - Pendapatan Per Kapita Masyarakat } \\
\text { - Proporsi Pendapatan untuk Kebutuhan } \\
\text { Tersier } \\
\text { - Angka Rata-rata Pertumbuhan Ekonomi per } \\
\text { Tahun } \\
\text { - Jumlah Biaya Rata-rata untuk Kesehatan per } \\
\text { Bulan }\end{array}$ & $\begin{array}{l}12 \% \\
5 \% \\
8 \% \\
10 \%\end{array}$ \\
\hline $\begin{array}{l}\text { Teknologi } \\
\text { - Jumlah Pengguna Mobile Phone } \\
\text { - Harga Rata-rata Paket Internet Mobile } \\
\text { Phone per Bulan } \\
\text { - Jumah Wireless Router }\end{array}$ & $\begin{array}{l}13 \% \\
8 \% \\
9 \%\end{array}$ \\
\hline $\begin{array}{l}\text { Sosial } \\
\text { - Jumlah Masyarakat Miskin } \\
\text { - Jumlah Perbandingan Hospital Bed per } \\
\text { 10,000 populasi } \\
\text { - Jarak Rata-rata Rumah Penduduk dengan } \\
\quad \text { Rumah Sakit }\end{array}$ & $\begin{array}{l}7 \% \\
9 \% \\
4 \%\end{array}$ \\
\hline $\begin{array}{l}\text { Organisasi } \\
\text { - Anggaran Pemerintah untuk Kesehatan } \\
\text { - Anggaran Pemerintah untuk Teknologi }\end{array}$ & $\begin{array}{l}7.5 \% \\
7.5 \%\end{array}$ \\
\hline
\end{tabular}

TABEL IV

CONTOH PENGELOMPOKKAN DATA PADA INDIKATOR PENDAPATAN PER KAPITA MASYARAKAT

\begin{tabular}{cc}
\hline Rating & Parameter biaya \\
\hline 1 & $0-500.000$ \\
2 & $500.001-1.000 .000$ \\
3 & $1.000 .001-1.500 .000$ \\
4 & $1.500 .001-2.000 .000$ \\
5 & $2.000 .001-2.500 .000$ \\
6 & $2.500 .001-3.000 .000$ \\
7 & $3.000 .001-3.500 .000$ \\
8 & $3.500 .001-4.000 .000$ \\
9 & $4.000 .001-4.500 .000$ \\
10 & $4.500 .001-5.000 .000$ \\
\hline
\end{tabular}

Peneliti menggunakan metode pengambilan data sekunder dari berbagai macam sumber. Data yang didapat berasal dari badan-badan resmi penyedia data yang terdapat di Indonesia, India, Amerika, dan Australia. Data tersebut langsung dikonversikan menjadi rating, yang selanjutnya digunakan untuk penyusunan nilai dalam weighted score matrix. Tabel IV menunjukkan rating untuk parameter pendapatan per kapita masyarakat.

\section{Hasil dan Analisis}

Data-data yang telah didapatkan pada saat pengumpulan data, selanjutnya diolah menggunakan weighted score matrix dengan indikator dan bobot yang telah dijelaskan pada bagian metodologi penelitian.

Negara yang akan dijadikan sebagai negara pembanding dalam penelitian ini adalah negara yang telah menerapkan $m$-Health dengan baik, yaitu India, Australia, dan Amerika. Penghitungan weighted score matrix dengan masukan berupa data-data negara pembanding, ditampilkan pada tabel V sampai dengan tabel VII.

Setelah dilakukan perhitungan terhadap negara pembanding, dilakukan perhitungan untuk negara yang akan diukur tingkat kelayakan penerapan $m$-Health nya, yakni Indonesia. Perhitungan menggunakan model yang sama seperti perhitungan sebelumnya. Hasil perhitungan dapat dilihat pada tabel VIII.

Hasil analisis menunjukkan bahwa nilai weighted score untuk Indonesia lebih rendah dari ketiga negara lainnya. Indonesia mendapatkan nilai 456.5, sedangkan India mendapatkan nilai 494, nilai Australia 566, dan nilai Amerika 552.5. Hasil ini menunjukkan bahwa penerapan mHealth di Indonesia tidak lebih baik dari penerapan m-Health di India, Australia, maupun Amerika.

Berdasarkan permodelan weighted score matrix yang digunakan, dapat diketahui bahwa kelemahan Indonesia dalam hal penerapan mHealth terletak pada aspek teknologi dan organisasi. Dari dua aspek tersebut, perbedaan nilai indikator yang paling signifikan terdapat pada indikator jumlah pengguna mobile phone dan anggaran pemerintah untuk teknologi. Dalam hal ini, untuk meningkatkan nilai kelayakan penerapan m-Health di Indonesia, minimal diperlukan adanya peningkatan jumlah pengguna mobile phone serta anggaran pemerintah untuk teknologi. 


\section{Total Weighted Score}

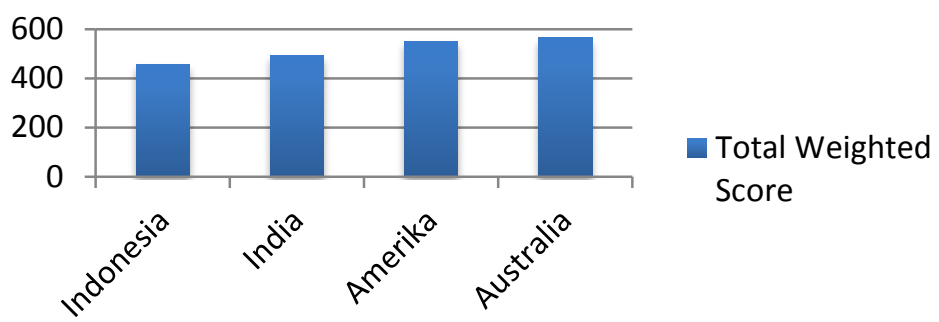

Gambar 1. Total weighted score untuk Indonesia, India, Amerika, dan Australia

TABEL V

PENGHITUNGAN WEIGHTED SCORE MATRIX UNTUK NEGARA INDIA

\begin{tabular}{|c|c|c|c|}
\hline Faktor Kelayakan & Weight & Rating & Weighted Score \\
\hline $\begin{array}{l}\text { Ekonomi } \\
\text { - Pendapatan Per Kapita Masyarakat } \\
\text { - Proporsi Pendapatan untuk Kebutuhan Tersier } \\
\text { - Rata-rata Pertumbuhan Ekonomi per Tahun } \\
\text { - Jumlah Biaya Rata-rata untuk Kesehatan per Bulan }\end{array}$ & $\begin{array}{l}12 \% \\
5 \% \\
8 \% \\
10 \%\end{array}$ & $\begin{array}{l}3 \\
8 \\
6 \\
3\end{array}$ & $\begin{array}{l}36 \\
40 \\
48 \\
30\end{array}$ \\
\hline $\begin{array}{l}\text { Teknologi } \\
\text { - Jumlah Pengguna Mobile Phone } \\
\text { - Harga Rata-rata Paket Internet Mobile Phone per Bulan } \\
\text { - Jumah Wireless Router }\end{array}$ & $\begin{array}{l}13 \% \\
8 \% \\
9 \%\end{array}$ & $\begin{array}{l}7 \\
8 \\
6\end{array}$ & $\begin{array}{l}91 \\
64 \\
54\end{array}$ \\
\hline $\begin{array}{l}\text { Sosial } \\
\text { - Jumlah Masyarakat Miskin } \\
\text { - Jumlah Perbandingan Hospital Bed per 10,000 populasi } \\
\text { - Jarak Rata-rata Rumah Penduduk dengan Rumah Sakit }\end{array}$ & $\begin{array}{l}7 \% \\
9 \% \\
4 \%\end{array}$ & $\begin{array}{l}3 \\
3 \\
2\end{array}$ & $\begin{array}{c}21 \\
27 \\
8\end{array}$ \\
\hline $\begin{array}{l}\text { Organisasi } \\
\text { - Anggaran Pemerintah untuk Kesehatan } \\
\text { - Anggaran Pemerintah untuk Teknologi }\end{array}$ & $\begin{array}{l}7.5 \% \\
7.5 \%\end{array}$ & $\begin{array}{l}3 \\
7\end{array}$ & $\begin{array}{l}22.5 \\
52.5\end{array}$ \\
\hline Total Weighted Score & & & 494 \\
\hline
\end{tabular}

TABEL VI

PENGHITUNGAN WEIGHTED SCORE MATRIX UNTUK NEGARA AMERIKA

\begin{tabular}{|c|c|c|c|}
\hline Faktor Kelayakan & Weight & Rating & Weighted Score \\
\hline \multicolumn{4}{|l|}{ Ekonomi } \\
\hline - Pendapatan Per Kapita Masyarakat & $12 \%$ & 9 & 108 \\
\hline - Proporsi Pendapatan untuk Kebutuhan Tersier & $5 \%$ & 10 & 50 \\
\hline - Rata-rata Pertumbuhan Ekonomi per Tahun & $8 \%$ & 1 & 8 \\
\hline - Jumlah Biaya Rata-rata untuk Kesehatan per Bulan & $10 \%$ & 6 & 60 \\
\hline \multicolumn{4}{|l|}{ Teknologi } \\
\hline - Jumlah Pengguna Mobile Phone & $13 \%$ & 5 & 65 \\
\hline - Harga Rata-rata Paket Internet Mobile Phone per Bulan & $8 \%$ & 1 & 8 \\
\hline - Jumah Wireless Router & $9 \%$ & 10 & 90 \\
\hline \multicolumn{4}{|l|}{ Sosial } \\
\hline - Jumlah Masyarakat Miskin & $7 \%$ & 7 & 49 \\
\hline - Jumlah Perbandingan Hospital Bed per 10,000 populasi & $9 \%$ & 3 & 27 \\
\hline - Jarak Rata-rata Rumah Penduduk dengan Rumah Sakit & $4 \%$ & 5 & 20 \\
\hline \multicolumn{4}{|l|}{ Organisasi } \\
\hline - Anggaran Pemerintah untuk Kesehatan & $7.5 \%$ & 5 & 37.5 \\
\hline - Anggaran Pemerintah untuk Teknologi & $7.5 \%$ & 4 & 30 \\
\hline \multicolumn{3}{|c|}{ Total Weighted Score } & 552.5 \\
\hline
\end{tabular}


TABEL VII

PENGHITUNGAN WEIGHTED SCORE MATRIX UNTUK NEGARA AUSTRALIA

\begin{tabular}{|c|c|c|c|}
\hline Faktor Kelayakan & Weight & Rating & Weighted Score \\
\hline \multicolumn{4}{|l|}{ Ekonomi } \\
\hline - Pendapatan Per Kapita Masyarakat & $12 \%$ & 9 & 108 \\
\hline - Proporsi Pendapatan untuk Kebutuhan Tersier & $5 \%$ & 9 & 45 \\
\hline - Rata-rata Pertumbuhan Ekonomi per Tahun & $8 \%$ & 1 & 8 \\
\hline - Jumlah Biaya Rata-rata untuk Kesehatan per Bulan & $10 \%$ & 6 & 60 \\
\hline \multicolumn{4}{|l|}{ Teknologi } \\
\hline - Jumlah Pengguna Mobile Phone & $13 \%$ & 10 & 130 \\
\hline - Harga Rata-rata Paket Internet Mobile Phone per Bulan & $8 \%$ & 1 & 8 \\
\hline - Jumah Wireless Router & $9 \%$ & 5 & 45 \\
\hline \multicolumn{4}{|l|}{ Sosial } \\
\hline - Jumlah Masyarakat Miskin & $7 \%$ & 7 & 49 \\
\hline - Jumlah Perbandingan Hospital Bed per 10,000 populasi & $9 \%$ & 7 & 63 \\
\hline - Jarak Rata-rata Rumah Penduduk dengan Rumah Sakit & $4 \%$ & 5 & 20 \\
\hline \multicolumn{4}{|l|}{ Organisasi } \\
\hline - Anggaran Pemerintah untuk Kesehatan & $7.5 \%$ & 3 & 22.5 \\
\hline - Anggaran Pemerintah untuk Teknologi & $7.5 \%$ & 1 & 7.5 \\
\hline Total Weighted Score & & & 566 \\
\hline
\end{tabular}

TABEL VIII

PENGHITUNGAN WEIGTHED SCORE MATRIX UNTUK NEGARA INDONESIA

\begin{tabular}{|c|c|c|c|}
\hline Faktor Kelayakan & Weight & Rating & Weighted Score \\
\hline \multicolumn{4}{|l|}{ Ekonomi } \\
\hline - Pendapatan Per Kapita Masyarakat & $12 \%$ & 6 & 72 \\
\hline - Proporsi Pendapatan untuk Kebutuhan Tersier & $5 \%$ & 9 & 45 \\
\hline - Angka Rata-rata Pertumbuhan Ekonomi per Tahun & $8 \%$ & 4 & 32 \\
\hline - Jumlah Biaya Rata-rata untuk Kesehatan per Bulan & $10 \%$ & 5 & 50 \\
\hline \multicolumn{4}{|l|}{ Teknologi } \\
\hline - Jumlah Pengguna Mobile Phone & $13 \%$ & 6 & 78 \\
\hline - Harga Rata-rata Paket Internet Mobile Phone per Bulan & $8 \%$ & 4 & 32 \\
\hline - Jumah Wireless Router & $9 \%$ & 1 & 9 \\
\hline \multicolumn{4}{|l|}{ Sosial } \\
\hline - Jumlah Masyarakat Miskin & $7 \%$ & 3 & 21 \\
\hline - Jumlah Perbandingan Hospital Bed per 10,000 populasi & $9 \%$ & 3 & 27 \\
\hline - Jarak Rata-rata Rumah Penduduk dengan Rumah Sakit & $4 \%$ & 2 & 8 \\
\hline \multicolumn{4}{|l|}{ Organisasi } \\
\hline - Anggaran Pemerintah untuk Kesehatan & $7.5 \%$ & 8 & 60 \\
\hline - Anggaran Pemerintah untuk Teknologi & $7.5 \%$ & $\begin{array}{l}0 \\
3\end{array}$ & 22.5 \\
\hline \multicolumn{3}{|l|}{ Total Weighted Score } & 456.5 \\
\hline
\end{tabular}

\section{Kesimpulan dan Saran}

Berdasarkan analisis terhadap data yang telah didapat dengan menggunakan metode weighted score matrix, maka dapat diambil kesimpulan sehubungan dengan tujuan penelitian, yaitu: Penerapan teknologi $m$-Health di Indonesia belum seoptimal penerapan $m$-Health di India, jika diterapkan dalam kondisi saat ini sesuai dengan indikator-indikator Health Technology Assessment; Belum optimalnya penerapan teknologi $m$-Health di Indonesia menunjukkan bahwa beberapa faktor dari aspek sosial, ekonomi, teknologi, organisasi milik Indonesia belum lebih baik dari negara India yang merupakan salah satu pelopor penerapan m-Health; serta Nilai kelayakan penerapan teknologi m-Health di Indonesia dapat ditingkatkan dengan memperbaiki nilai indikator-indikator yang belum optimal.

Saran-saran yang didapat dari peneliti ajukan untuk penelitian sejenis selanjutnya diantaranya, pengujian dengan metode yang berbeda, perluasan aspek-aspek penilaian kelayakan, dan penelitian untuk studi kasus negara lain.

\section{Referensi}


[1] K. Wu \& X. Wu, "A Wireless Mobile Monitoring System for Home Healthcare and Community Medical Services" In ICBEE 2007, pp. 1190-1193, 2007.

[2] C. Rokx, J. Giles, E. Satriawan, P. Marzoeki, \& P. Harimurti, "New Insights Into the Provision of Health Services in Indonesia : A Health Workfoce Study," Directions in Development Human Development, vol. 53883, pp. 160, 2010.

[3] Vital Wave Consulting, "m-Health for Development: The Opportunity of Mobile Technology for Healthcare in the Developing World," Washington, D.C. and Berkshire, UK: UN Foundation-Vodafone Foundation Partnership, 2009.

[4] F. Mirza, T. Norris, \& R. Stockdale, "Mobile technologies and the holistic management of chronic diseases," Health Informatics Journal, vol. 14 (4), pp. 3309-321, 2008.

[5] A.M. Skulimowski, "The challenges to the medical decision making system posed by $m$ health," IPTS, Report, Progress and Business Foundation, no. 18, 2004, http://www.jrc.es/home/report/english/aritcle s/viol81/ICT81E816.htm, retrieved December 11, 2006.

[6] J.L. Funk, Mobile Disruption: The Technologies and Applications That Are Driving the Mobile Internet, Wiley, New York, 2003.

[7] C.M. Christensen, The Innovator's Dilemma : When New Technologies Cause Great Firms to Fail, Mass.: Harvard Business School Press, Boston, 1997.

[8] E. Draborg \& C.K. Andersen, "Recommendations in health technology assessments worldwide," International Journal of Technology Assessment in Health Care, vol. 22, pp. 155-160, 2006.

[9] E. Draborg, D. Gyrd-Hansen, P.B. Poulsen, $\&$ M. Horder, "International comparison of the definition and the practical application of health technology assessment," International Journal of Technology Assessment in Health Care, vol. 21, pp. 89-95, 2005. 